\title{
Antioxidant activity of ethyl acetate and methanolic extracts of two marine algae, Nannochloropsis oculata and Gracilaria gracilis - an in vitro assay
}

\author{
Mohammad Ali Ebrahimzadeh, Masoumeh Khalili, ${ }^{2, *}$, Abbas Ali Dehpour ${ }^{3}$
}

\begin{abstract}
${ }^{1}$ Pharmaceutical Sciences Research Center, School of Pharmacy, Mazandaran University of Medical Sciences, Sari, Iran, ${ }^{2}$ Neurosciences Research Center, Golestan University of Medical Sciences, Gorgan, Iran, ${ }^{3}$ Department of Biology, Islamic Azad University, Branch of Qaemshahr, Qaemshahr, Iran
\end{abstract}

\begin{abstract}
The aim of this study was to evaluate the antioxidant activity of ethyl acetate and methanolic extracts of two marine algae, Nannochloropsis oculata and Gracilaria gracilis. The extracts were assayed for total phenol and flavonoid content, DPPH free radical scavenging capacity, nitric oxide activity, iron chelation activity, and reducing power activity. Total phenol and flavonoid content were found to be high in both algae. Ethyl acetate extracts of both algae were found to exhibit significant antioxidant activity. Ethyl acetate extract of $N$. oculata exhibited a good capacity for iron chelation, nitrate oxide, and scavenging DPPH free radicals $\left(72.95 \pm 2.30,73.73 \pm 1.76\right.$, and $39.03 \pm 0.97 \%$ inhibition at $400 \mu \mathrm{g} \mathrm{mL}^{-1}$ respectively).
\end{abstract}

Keywords: Marine algae/antioxidant activity. Nannochloropsis Oculata/total phenol/total flavonoid/ Gracilaria Gracilis/total phenol/total flavonoid.

\section{INTRODUCTION}

Free radicals, which refer to any molecular species containing unpaired electron in an atomic orbital, are unstable elements amenable to take part in chemical reactions (Yangthong, Hutadilok-Towatana, Phromkunthong, 2009). Reactive oxygen, nitrogen and sulfur species are free that produce superoxide anion, hydroxyl radical, hydrogen peroxide and nitric oxide. These compounds may cause diseases as diverse as cancer, diabetes, Alzheimer, and Parkinson through inducing oxidative stresses, cell damage and death (Lü et al., 2010; Yangthong, Hutadilok-Towatana, Phromkunthong, 2009; Ebrahimzadeh, Safdari, Khalili, 2015). A huge number of natural compounds have been proven to exhibit antioxidant activity and be applicable for treatment of oxidative-damage related diseases. Large number of plants (e.g. Salvia virgate and Silybum marianum), fungi (e.g. Cantharellus cibarius) and alga (e.g. Ecklonia cava and Stoechospermum marginatum) are regarded as major

\footnotetext{
*Correspondence: M. Khalili. Neuroscience Research Center, Golestan University of Medical Sciences, Gorgan, Iran. Tel/Fax: +981732420515. E-mail address: mkhalili_phs@goums.ac.ir; mkhalili_ps@yahoo.com
}

sources of natural antioxidants (Ebrahimzadeh et al., 2016; Ebrahimzadeh, Safdari, Khalili, 2015; Khalili, Ebrahimzadeh, Kosaryan, 2015).

Recent studies have shown that marine algae are rich in bioactive compounds including polysaccharides, polyunsaturated fatty acids, polyphenolic compounds, antioxidants, peptides, essential vitamins and minerals (Kim et al., 2014; Fernando et al., 2017; Wang et al., 2017). These compounds exhibit wide range of pharmacological activities, including antioxidant, antibacterial, antifungal, anti-inflammatory, anti-aging, and anti-cancer activities (Mayer et al., 2009; Fernando et al., 2016; Agatonovic-Kustrin, Morton, 2017). In the current study, we evaluate the anti-oxidative activity of two marine alga, Nannochloropsis oculata and Gracilaria gracilis.

\section{MATERIAL AND METHODS}

\section{Chemicals}

Ferrozine, trichloroacetic acid, 1, 1-diphenyl-2picryl hydrazyl (DPPH), and potassium ferricyanide were purchased from Sigma Chemical Co. (Germany). 
butylated hydroxyanisole, ascorbic acid, sulfanilamide, $N$-(1-naphthyl)ethylenediamine dihydrochloride, ethylenediaminetetraacetic acid, and ferric chloride were purchased from Merck (Germany).

\section{Algae species}

N. oculata was cultivated to Walne medium (Walne 1970) (Table I). G. gracilis samples were kindly provided by Dr. Dehpour (Department of Biology, Islamic Azad University, Branch of Qaemshahr, Qaemshahr, Iran). The samples have been gathered from the beach of Persian Gulf (Bostaneh, Central District of Bandar Lengeh County, Hormozgan Province, Iran. Coordinates: 26³0'37"N

TABLE I - Walne media for cultivated $N$. oculata

\begin{tabular}{lc}
\hline Stocks & Per 100 $\mathbf{~ m L}$ \\
\hline (1) Trace metal solution (TMS) & \\
\hline $\mathrm{ZnCl} 2$ & $2.1 \mathrm{~g}$ \\
$\mathrm{CoCl}_{2 \cdot 6} \mathrm{HO}_{2}$ & $2.0 \mathrm{~g}$ \\
$\left(\mathrm{NH}_{4}\right)_{6} \mathrm{Mo}_{7} \mathrm{O}_{24} \cdot 4 \mathrm{HO}_{2}$ & $0.9 \mathrm{~g}$ \\
$\mathrm{CuSO}_{4} \cdot 5 \mathrm{H}_{2} \mathrm{O}$ & $2.0 \mathrm{~g}$ \\
\hline
\end{tabular}

Make up to $100 \mathrm{~mL}$ with distilled water. This solution is normally cloudy. Acidify with a few drops of conc. $\mathrm{HCl}$ to give a clear solution.

\begin{tabular}{lc}
\hline (2) Vitamin solution & \\
\hline Vitamin $\mathrm{B}_{12 .}$ (Cyanocobalamin) & $10.0 \mathrm{mg}$ \\
Vitamin $\mathrm{B}_{1}$ (Thiamine.HCl) & $10.0 \mathrm{mg}$ \\
Vitamin H (Biotin) & $200.0 \mu \mathrm{g}$ \\
Make up to $100 \mathrm{ml}$ with distilled water. & \\
\hline
\end{tabular}

\begin{tabular}{lc}
\hline (3) Nutrient solution & per litre \\
\hline $\mathrm{FeCl}_{3 \cdot 6} \mathrm{HO}_{2}$ & $1.3 \mathrm{~g}$ \\
$\mathrm{MnCl}_{2 \cdot 4} \mathrm{HO}_{2}$ & $0.36 \mathrm{~g}$ \\
$\mathrm{H}_{3} \mathrm{BO}$ & $33.6 \mathrm{~g}$ \\
$\mathrm{EDTA}($ Disodium salt $)$ & $45.0 \mathrm{~g}$ \\
$\mathrm{NaH}_{2} \mathrm{PO}_{4} \cdot 2 \mathrm{HO}_{2}$ & $20.0 \mathrm{~g}$ \\
$\mathrm{NaNO}_{3}$ & $100.0 \mathrm{~g}$ \\
$\mathrm{TMS}(1$ above) & $1.0 \mathrm{ml}$ \\
\hline
\end{tabular}

Make up to 1 litre with distilled water.

\begin{tabular}{lc}
\hline Medium & per litre \\
\hline Nutrient solution (3) & $1.0 \mathrm{~mL}$ \\
Vitamin solution (2) & $0.1 \mathrm{~mL}$ \\
Sterilised seawater & $1.0 \mathrm{~L}$ \\
\hline
\end{tabular}

Dispense nutrient and vitamin solutions separately into $10 \mathrm{~mL}$ and $1 \mathrm{~mL}$ respectively and autoclave at 15 psi for 15 minutes. Add an aliquot of each aseptically $10 \mathrm{~L}$ of sterilised seawater.
5439'20"E, 2015). G. gracilis samples were washed with water and then dried at $45^{\circ} \mathrm{C}$ for $24 \mathrm{~h}$ using forced convection drying oven.

\section{Preparation of methanolic and ethyl acetate extracts from N. oculata and G. gracilis}

Ethyl acetate extracts were obtained by percolating $10 \mathrm{~g}$ of powdered algae for $24 \mathrm{~h}$ at room temperature. The extracts were refined using Whatman filter paper (No. 1).The remaining samples were used to extract methanolic compounds. Both the extracts were filtered and then concentrated under reduced pressure at $40^{\circ} \mathrm{C}$ using a rotary evaporator. All extracts were dried by vacuum freeze dryer.

\section{Determination of total flavonoid and phenolic contents}

To quantity total flavonoids in the algae species, 0.5 $\mathrm{mL}$ of each algal extract (Concentration: $800 \mu \mathrm{g} \mathrm{mL}^{-1}$ ) was mixed with $1.5 \mathrm{~mL}$ methanol, $0.1 \mathrm{~mL} 1 \mathrm{M}$ potassium acetate, $0.1 \mathrm{~mL}$ aluminum chloride $10 \%$, and $2.8 \mathrm{~mL}$ distilled water, and then incubated at room temperature for $30 \mathrm{~min}$. The absorbance was measured at $415 \mathrm{~nm}$ by spectrophotometer. Total flavonoid content was calculated as quercetin equivalents (QE) from a calibration curve as described previously (Ebrahimzadeh, Safdari, Khalili, 2015). Total phenolic content was measured using Folin-Ciocalteu method. Summarily, the extracts $(0.5$ $\mathrm{mL}$ ) were mixed with $2.5 \mathrm{~mL}$ of Folin-Ciocalteau reagent $(0.2 \mathrm{~N})$ and $2.0 \mathrm{~mL}$ sodium carbonate (concentration of $75 \mathrm{~g} / \mathrm{L}$ ) and subjected to absorbance measuring at 760 nm (spectrophotometer (UV-Visible EZ201, Perkin Elmer, Norwalk, Connecticut). More details on the procedure can be found in our previously published article (Ebrahimzadeh, Safdari, Khalili, 2015). The results were expressed as gallic acid equivalents (GAE).

\section{Metal chelating activity assay}

Metal chelating activity assay has been described in our previous work (Ebrahimzadeh, Safdari, Khalili, 2015). Summarily, $1 \mathrm{~mL}$ of each extracts $\left(800 \mu \mathrm{g} \mathrm{mL} \mathrm{m}^{-1}\right)$ was mixed with $0.5 \mathrm{~mL}$ of $2 \mathrm{mM} \mathrm{FeCl}$ (II) solution, to which $0.2 \mathrm{~mL}$ of ferrozine $(5 \mathrm{mM})$ was added to initiate the reaction by adding. The absorbance of the solutions was measured at $562 \mathrm{~nm}$. EDTA was used as a standard.

\section{Nitric oxide scavenging activity assay}

$3 \mathrm{~mL}$ of each extract $\left(800 \mu \mathrm{g} \mathrm{mL}^{-1}\right)$ was added to 
$1 \mathrm{~mL}$ of sodium nitroprusside $(10 \mathrm{mM})$ and incubated at room temperature for $150 \mathrm{~min}$. Afterward, $0.5 \mathrm{~mL}$ Griess reagent $\left[1 \%\right.$ sulfanilamide, $2 \% \mathrm{H}_{3} \mathrm{PO}_{4}$, and $0.1 \% \mathrm{~N}$-(1naphthyl) ethylenediamine dihydro chloride] was added to the reaction and subjected to absorbance measuring at 546 $\mathrm{nm}$. Quercetin (a flavonoid compound, PubChem CID: 5280343) was used as a positive control (Ebrahimzadeh, Safdari, Khalili, 2015).

\section{DPPH radical scavenging activity}

DPPH radical scavenging activity was assayed as described previously (Ebrahimzadeh, Safdari, Khalili, 2015). Summarily, $2 \mathrm{~mL}$ of DPPH solution $(100 \mu \mathrm{M})$ was added to $2 \mathrm{~mL}$ of each fraction (concentration of $800 \mu \mathrm{g}$ $\mathrm{mL}^{-1}$ ) and then incubated at room temperature for $15 \mathrm{~min}$, the absorbance was recorded at $517 \mathrm{~nm}$. The reaction was then subjected to absorbance measuring at $517 \mathrm{~nm}$. BHA was used as standard control.

\section{Reducing power assay}

Each extract (at different concentrations, ranging from 100 to $1600 \mu \mathrm{g} \mathrm{mL}^{-1}$ ) was mixed with $1 \mathrm{~mL}$ potassium hexacyanoferrate and $1 \mathrm{~mL}$ phosphate buffer $(0.2 \mathrm{M}, \mathrm{pH}$ 6.6) $(1 \%)$, incubated at $50^{\circ} \mathrm{C}$ (in a water bath) for $20 \mathrm{~min}$, and then received To terminate the reaction, $1 \mathrm{~mL}$ of TCA $(10 \%)$ was added to each reaction. The upper portion of the solution $(1 \mathrm{~mL})$ was mixed with $1 \mathrm{~mL}$ distilled water and $0.2 \mathrm{~mL}$ iron (III) chloride solution $(0.1 \%)$ and subjected to absorbance measuring at $700 \mathrm{~nm}$ (Ebrahimzadeh, Safdari, Khalili, 2015).

\section{Statistical analysis}

All the experiments included in this study were done in triplicate and the results expressed as means \pm SD. The data were analyzed through one-way analysis of variance (ANOVA) using GrphPad Prism. The means were compared using Tukey multiple comparisons test $(\mathrm{p}<0.05)$.

\section{RESULTS AND DISCUTION}

\section{Ethyl acetate and methanolic extracts of $\mathbf{N}$. oculata and G. gracilis}

The maximum and the minimum extraction efficiencies belonged to ethyl acetate extract of $G$. gracilis and methanolic extract of G. gracilis, 0.016 and $0.059 \mathrm{~g} / \mathrm{g}$ DW, respectively. Extraction efficiencies for ethyl acetate and methanolic extracts of $N$. oculata were calculated to be 4.54 and $5.15 \%$, respectively.

\section{Total flavonoid and phenolic contents}

Total flavonoid content of all the extracts is shown in Table II. Ethyl acetate extracts of both $N$. oculata and G. gracilis species were found to be rich in flavonoid compounds $(71.79 \pm 2.32$ and $66.48 \pm 1.87 \mathrm{mg}$ quercetin equivalent $\mathrm{g}^{-1}$ of extract, respectively) while their methanolic extracts were found to contain less amounts of flavonoid compounds (42.08 \pm 1.09 and $26.47 \pm 1.203 \mathrm{mg}$ quercetin equivalent $\mathrm{g}^{-1}$ of extract, respectively).

Total phenol content was calculated using FolinCiocalteau method and linear gallic acid standard curve $(y=0.0054 x+0.0623 ; r=1)$. The content of total phenols in the algal species is shown in Table II. The maximum and the minimum amounts of phenolic compounds belonged to ethyl acetate extract of $N$. oculata and methanolic extract of the G. gracilis $41.45 \pm 1.42$ and $29.39 \pm 2.01 \mathrm{mg}$ gallic acid equivalent $\mathrm{g}^{-1}$ of extract, respectively (Table II). Total phenol content of methanolic extract of $N$. oculata and ethyl acetate extract of $G$. gracilis were calculated to be $30.94 \pm 1.61$ and $35.53 \pm 1.47 \mathrm{mg}$ gallic acid equivalent $\mathrm{g}^{-1}$ of extract, respectively.

We found the maximum phenolic compounds in ethyl acetate extract of algal species. Our results are consistent with the results of Duan et al. (2006). However, our findings are inconsistent with the reports of Farasat et al. (2014). They evaluated the total phenol and flavonoid content of some algae species driven from northern coasts of the Persian Gulf, and showed that methanolic extracts contain higher levels of flavonoid content.

Both phenolic and flavonoid compounds have been demonstrated to exhibit wide range of advantageous biological activities, including antioxidant activity, free radical scavenging activity, anti-cancer and antiatherosclerotic activities, and so forth (Balasundram, Sundram, Samman, 2006; Cox, Abu-Ghannam, Gupta, 2010; Duan et al., 2006; Li et al., 2007; Fernando et al., 2016).

\section{Iron chelation activity}

Ethyl acetate extracts of both algae species were found to have higher iron chelation activity than their methanolic extracts. . The maximum and the minimum iron chelation activities belonged to ethyl acetate extract of $N$. oculata (and the methanolic extract of G. gracilis $72.95 \pm 2.30$ and $19.49 \pm 1.46 \%$ inhibition at $400 \mu \mathrm{g} \mathrm{mL}^{-1}$, respectively. The correlation coefficient $\left(r^{2}\right)$ between 
TABLE II -Total phenol and flavonoid contents and antioxidant activities of ethyl acetate and methanolic extract of $N$. oculata and G. gracilis

\begin{tabular}{|c|c|c|c|c|c|}
\hline \multirow{2}{*}{\multicolumn{2}{|c|}{$\begin{array}{l}\text { Sample name } \\
\text { Extract }\end{array}$}} & \multicolumn{2}{|c|}{ N. oculata } & \multicolumn{2}{|c|}{ G. gracilis } \\
\hline & & Ethyl acetate extract & Methanolic extract & Ethyl acetate extract & Methanolic extract \\
\hline \multicolumn{2}{|l|}{ EFFICIENCY (g/g DW) } & 0.045 & 0.051 & 0.016 & 0.059 \\
\hline \multicolumn{2}{|c|}{$\begin{array}{l}\text { Total Flavonoid content (mg quercetin } \\
\text { equivalent } \mathrm{g}^{-1} \text { of extract) }\end{array}$} & $71.79 \pm 2.32$ & $42.08 \pm 1.09$ & $66.48 \pm 1.87$ & $26.47 \pm 1.203$ \\
\hline \multicolumn{2}{|c|}{$\begin{array}{l}\text { Total Phenol content ( } \mathrm{mg} \text { gallic acid } \\
\text { equivalent } \mathrm{g}^{-1} \text { of extract) }\end{array}$} & $41.45 \pm 1.42$ & $30.94 \pm 1.61$ & $35.53 \pm 1.47$ & $29.39 \pm 2.01$ \\
\hline Iron chelation activity* & percentage of & $72.95 \pm 2.30$ & $29.71 \pm 1.98$ & $49.71 \pm 1.93$ & $19.49 \pm 1.46$ \\
\hline Nitric Oxide activity ** & inhibition at & $73.73 \pm 1.76$ & $65.6 \pm 1.54$ & $65.33 \pm 2.54$ & $34.8 \pm 1,59$ \\
\hline $\mathrm{DPPH}^{* * *}$ & $400 \mu \mathrm{g} \mathrm{mL}^{-1}$ & $39.03 \pm 0.97$ & $21.68 \pm 1.41$ & $20.48 \pm 0.38$ & $17.4 \pm 1.34$ \\
\hline
\end{tabular}

Each value is the mean of three replicate determinations $\pm \mathrm{SD} ;{ }^{*}$ EDTA was used as control (IC50 =18.27 $\left.\pm 0.09 \mu \mathrm{g} \mathrm{mL}{ }^{-1}\right) ; * *$ Quercetin was used as control (IC50 $=5.28 \pm 0.2 \mu \mathrm{g} \mathrm{mL}^{-1}$ ); $* * *$ BHA was used as control (IC50 $=53.96 \pm 3.1 \mu \mathrm{g} \mathrm{mL}^{-1}$ ).

iron chelation activity and either "total phenol" or "flavonoid content "was calculated to b 0.99 and 0.89 , respectively.

Studies show that algae are rich in compounds with significant iron chelation activity (Bermejo, Piñero, Villar, 2008). Metal chelation ability depends on the type (flavonoid and phenolic acid), structure, and the number of available hydroxyl groups (Wang, Jónsdóttir, Ólafsdóttir, 2009).

\section{Nitric oxide activity}

Nitric oxide activity of the algal extracts at concentration of $400 \mu \mathrm{g} \mathrm{mL}^{-1}$ for ethyl acetate extract of $N$. oculata, the methanolic extract of $N$. oculata, the ethyl acetate extract of $G$. gracilis, and ethyl acetate extract of G. gracilis were calculated to be $73.73 \pm 1.7 \%, 65.6 \pm 1.54$, $65.33 \pm 2.54$ and $34.8 \pm 1.59 \%$ inhibition respectively. There was a low correlation between nitric oxide activity and either total phenol or flavonoid contents $\left(\mathrm{r}^{2}=0.56\right.$ and $r^{2}=0.69$ respectively). Reactive oxygen and nitrogen species are two main sources of oxidative substances, including hydrogen peroxide, superoxide, nitric oxide and peroxynitrite $\left(\mathrm{ONOO}^{-}\right)$. These substances can damage proteins, lipids and DNA. (Thanigaivel et al., 2016).

\section{DPPH radical scavenging activity}

DPPH color change from purple -to- yellow is an index for radical-scavenging activity, the more intense color transformation the higher scavenging activity is expected (Gontijo et al., 2012). As shown Table II, the highest DPPH radical scavenging activity belonged to the ethyl acetate extract of $N$. oculata $(39.03 \pm 0.97 \%$ inhibition at $400 \mu \mathrm{g} \mathrm{mL}^{-1}$ ) and the lowest activity belonged to methanolic extract of $G$. gracilis (17.4 $\pm 1.34 \%$ inhibition at $400 \mu \mathrm{g} \mathrm{mL}^{-1}$ ). Methanolic extract of $N$. oculata and ethyl acetate extract of $G$. gracilis (at concentration of $400 \mu \mathrm{g} \mathrm{mL}^{-1}$ ) were found to inhibit DPPH free radicals up to $21.68 \pm 1.41$ and $20.48 \pm 0.38 \%$, respectively. DPPH was found to have a high correlation $\left(\mathrm{r}^{2}=0.81\right)$ with total phenolic compounds but not with total flavonoid compounds $\left(\mathrm{r}^{2}=0.49\right)$. These findings are consistent with the results of our previous study (carried out on Cantharellus cibarius) and also with the results of Orhan and Üstün who investigated the correlation of phenol content and antioxidant activity of some Turkey mushrooms (Ebrahimzadeh, Safdari, Khalili, 2015; Orhan, Üstün, 2011; Duan et al., 2006).

\section{Reducing power activity}

Reducing power, which is an index for antioxidant activity, can be measured using a reaction in which $\mathrm{Fe}^{3+}$ in potassium ferricyanide is converted into $\mathrm{Fe}^{2+}$. The reaction product is measured using spectrophotometer at $\lambda=700$ nm (Sharma, Gujral, Singh, 2012; Gontijo et al., 2012). As shown in Figure 1, reducing power of all the extracts increased in a dose dependent manner. In both $N$. oculata and G. gracilis species, ethyl acetate extracts werefound to have higher reduction capacity than methanolic extract (Figure 1). The least reduction power belonged Methanolic extract of G. gracilis. Vitamin C (the control) reached a plateau at concentration of $800 \mu \mathrm{g} / \mathrm{ml}^{-1}(\mathrm{OD}=0.401)$, whereas the ethyl acetate extract of $N$. oculata and methanolic extract of $G$. gracilis exceeded this value and produced OD values of 0.73 and 0.531 , respectively. At concentration of $1600 \mu \mathrm{g} / \mathrm{ml}^{-1}$ reducing power was found 


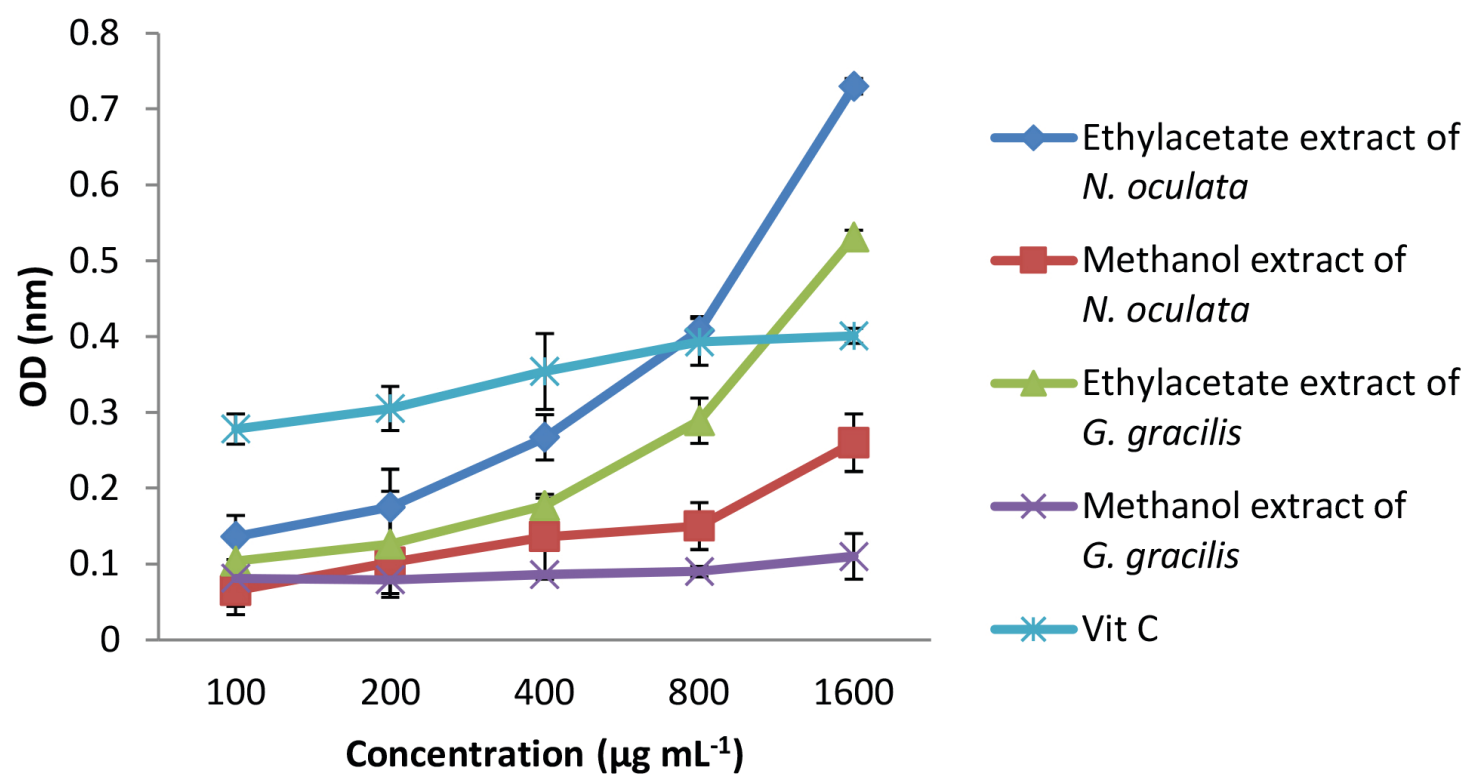

FIGURE 1 - Reducing power of ethyl acetate and methanolic extracts of algal species. Each point on the graphs represents the mean of three repetitions.

to have a potent coloration with total phenolic $\left(\mathrm{r}^{2}=0.98\right)$ and flavonoid $\left(\mathrm{r}^{2}=0.92\right)$ compounds. Phenolic compounds and flavonoids are electron donor substances that play an important role in exhibiting reduction capacity (Sharma, Gujral, Singh, 2012). Therefore, high coloration between reducing power and total phenolic and flavonoid content may be a reason for high reducing power activity.

Irudayaraj and colleagues (2012) reported that ethyl acetate extract driven from leaves of Toddalia asiatica has potential anti-diabetic and antioxidant capacities. Al-Saeedi, Al- Ghafri, Hossain (2016) reported that the ethyl acetate extract of Ziziphus jujuba L. has high levels of phenolic and flavonoid compounds. Therefore, the ethyl acetate extracts of $N$. oculata and G. gracilis could be used as a natural antioxidant for the treatment of different diseases related with free radicals and oxidative stress.

\section{CONCLUSION}

Ethyl acetate extracts of Nannochloropsis oculata and Gracilaria gracilis algae have considerable amounts of phenolic and flavonoid compounds. Ethyl acetate extracts driven from the both algae species exhibit significant antioxidant activity. There is a good correlation between total phenols and flavonoids content and iron chelation activity

\section{ACKNOWLEDGMENTS}

This research was supported by a grant from the research council of Medical Sciences University of Mazandaran, Iran.

\section{REFERENCES}

Agatonovic-Kustrin S, Morton DWJ. Quantification of polyphenolic antioxidants and free radical scavengers in marine algae. J Appl Phycol. 2017;29:1-8.

Al-Saeedi AH, Al- Ghafri MTH, Hossain MA. Comparative evaluation of total phenols, flavonoids content and antioxidant potential of leaf and fruit extracts of Omani Ziziphus jujuba L. PSRA. 2016;18(1):78-83.

Balasundram N, Sundram K, Samman S. Phenolic compounds in plants and agri-industrial by-products: antioxidant activity, occurrence, and potential uses. Food Chem. 2006;99(1):191203.

Bermejo P, Piñero E, Villar ÁM. Iron-chelating ability and antioxidant properties of phycocyanin isolated from a protean extract of Spirulinaplatensis. Food Chem. 2008;110(2):436-45.

Cox S, Abu-Ghannam N, Gupta S. An assessment of the antioxidant and antimicrobial activity of six species of edible Irish seaweeds. Int Food Res J. 2010;17:205-20.

Duan, XJ, Zhang, WW, Li XM, Wang BG. Evaluation of antioxidant property of extract and fractions obtained from a red alga, Polysiphonia urceolata. Food Chem. 2006;95(1):37-43. 
Ebrahimzadeh MA, Khalili M, Azadbakht M, Azadbakht M. Salvia virgata JACQ. and silibum marianum L. gaertn display significant iron-chelating activity. Int J Pharm Sci Res. 2016;9(7):3756-63.

Ebrahimzadeh MA, Safdari Y, Khalili M. Antioxidant activity of different fractions of methanolic extract of the golden chanterelle mushroom Cantharellus cibarius (higher basidiomycetes) from Iran. Int J Med Mushrooms. 2015,17(6):557-65.

Farasat M, Khavari-Nejad RA, Nabavi SMB, Namjooyan F. Antioxidant activity, total phenolics and flavonoid contents of some edible green seaweeds from Northern coasts of the Persian Gulf. Iran J Pharm Res. 2014;13(1):163-70.

Fernando IS, Kim M, Son KT, Jeong Y, Jeon YJ. Antioxidant activity of marine algal polyphenolic compounds: a mechanistic approach. J Med Food. 2016;19(7):615-28.

Fernando IS, Sanjeewa KA, Samarakoon KW, Lee WW, Kim HS, Kim EA, Gunasekara U, Abeytunga D, Nanayakkara C, Silva E. FTIR characterization and antioxidant activity of water soluble crude polysaccharides of Sri Lankan marine algae. Algae. 2017;32(1):75-86.

Gontijo VS, Souza TC, Rosa IA, Soares MG, Silva MA, Vilegas W, Viegas C, Santos MH. Isolation and evaluation of the antioxidant activity of phenolic constituents of the Garcinia brasiliensis epicarp. Food Chem. 2012;132(3):1230-5.

Irudayaraj SS, Sunil C, Duraipandiyan V, Ignacimuthu S. Antidiabetic and antioxidant activities of Toddalia asiatica (L.) Lam. leaves in Streptozotocin induced diabetic rats. J Ethnopharmacol. 2012;143(2):515-23.

Khalili M, Ebrahimzadeh MA, Kosaryan M. In vivo ironchelating activity and phenolic profiles of the Angel's Wings Mushroom, Pleurotus porrigens (Higher Basidiomycetes). Int J Med Mushrooms. 2015;17(9):847-56.

Kim SY, Kim EA, Kang MC, Lee JH, Yang HW, Lee JS, Lim TI, Jeon YJ. Polyphenol-rich fraction from Ecklonia cava (a brown alga) processing by-product reduces LPS-induced inflammation in vitro and in vivo in a zebrafish model. Algae. 2014;29(2):165-74.

Li HB, Cheng KW, Wong CC, Fan KW, Chen F, Jiang Y. Evaluation of antioxidant capacity and total phenolic content of different fractions of selected microalgae. Food Chem. 2007;102(3):771-6.
Lü JM, Lin PH, Yao Q, Chen C. Chemical and molecular mechanisms of antioxidants: experimental approaches and model systems. J Cell Mol Med. 2010;14(4):840-60.

Mayer AM, Rodríguez AD, Berlinck RG, Hamann MT. Marine pharmacology in 2005-6: marine compounds with anthelmintic, antibacterial, anticoagulant, antifungal, anti-inflammatory, antimalarial, antiprotozoal, antituberculosis, and antiviral activities; affecting the cardiovascular, immune and nervous systems, and other miscellaneous mechanisms of action. Biochim Biophys Acta. 2009;1790(5):283-308.

Orhan I, Üstün O. Determination of total phenol content, antioxidant activity and acetylcholinesterase inhibition in selected mushrooms from Turkey. J Food Comp Anal. 2011;24(3):386-90.

Sharma P, Gujral HS, Singh B. Antioxidant activity of barley as affected by extrusion cooking. Food Chem. 2012;131(4):140613.

Thanigaivel S, Chandrasekaran N, Mukherjee A, John T. Seaweeds as an alternative therapeutic source for aquatic disease management. Aquaculture. 2016;464:529-36.

Walne PR. Studies on the food value of nineteen genera of algae to juvenile bivalves of the genera Ostrea, Crassostrea, Mercenaria, and Mytilis. Fish Invest. 1970;26:162.

Wang, T, Jónsdóttir R, Ólafsdóttir G. Total phenolic compounds, radical scavenging and metal chelation of extracts from Icelandic seaweeds. Food Chem. 2009;116(1):240-8.

Wang H-MD, Li X-C, Lee D-G, Chang J-S. Potential biomedical applications of marine algae. Bioresour Technol., 2017. [In press].

Yangthong M, Hutadilok-Towatana N, Phromkunthong W. Antioxidant activities of four edible seaweeds from the southern coast of Thailand. Plant Foods Hum Nutr. 2009;64(3):218-23.

Received for publication on $16^{\text {th }}$ May 2017 Accepted for publication on $07^{\text {th }}$ August 2017 